\title{
Masalah emosi dan perilaku remaja: Studi awal masalah kesehatan mental di Kabupaten Pamekasan, Indonesia
}

\author{
Nandy Agustin Syakarofath \\ ${ }^{(1)}$ Fakultas Psikologi, Universitas Muhammadiyah Malang, Malang, Indonesia \\ Every individual tends to experience difficult adolescence because this developmental \\ period is typically characterized by mental turmoil, especially amid rapid changes in \\ current social, cultural and economic conditions. The purpose of this research was to \\ explore how much gender can explain the mental health status of adolescents in terms of \\ their emotional and behavioural problems. Participants in this research were 237 \\ adolescents aged 15-18 years in Pamekasan, which were selected using simple random \\ sampling. Designed as descriptive quantitative research, the data showed that the \\ majority of male and female adolescents demonstrated a fairly serious level of conduct \\ disorder. Meanwhile, in terms of emotional problems, the difficulties faced by the \\ majority of male and female adolescents pertained to peer problems. These empirical \\ findings point to the importance of solving male and female adolescents' emotional and \\ behavioural problems, to help them have adequate mental health.
}

Keywords: behavioural problems, emotional problems, male and female adolescents, mental health.

Setiap individu cenderung mengalami masa remaja yang sulit karena masa perkembangan ini ditandai dengan penuh gejolak psikologis terutama di tengah perubahan cepat dalam kondisi sosial, budaya dan ekonomi pada saat ini. Tujuan penelitian ini adalah untuk mengetahui status kesehatan mental remaja dari segi masalah emosi dan perilaku mereka atas dasar gender. Subjek penelitian adalah 237 remaja berusia 15-18 tahun di Pamekasan, yang dipilih amenggunakan teknik simple random sampling. Desain penelitian adalah deskriptif kuantitatif. Data penelitian menunjukkan bahwa mayoritas remaja laki-laki dan perempuan dalam penelitian ini memiliki tingkat kesulitan yang cukup serius (abnormal) pada masalah perilaku berupa conduct disorder. Sementara itu, pada masalah emosional, berbagai kesulitan yang dihadapi mayoritas remaja laki-laki dan perempuan berupa peer problem. Implikasi dari hasil penelitian ini mengarah pada pentingnya penanganan masalah-masalah emosi dan perilaku pada remaja laki-laki maupun perempuan agar mereka bisa memiliki kesehatan mental yang memadai.

Kata kunci: kesehatan mental, masalah emosi, masalah perilaku, remaja laki-laki dan perempuan

MEDIAPSI, 2021, Vol. 7(2), 141-149, DOI: https://doi.org/10.21776/ub.mps.2021.007.02.6

Received: 04-05-2021. Revised: 11-11-2021. Accepted: 26-11-2021. Published online: 25-12-2021

Handling Editor: Ziadatul Hikmiah, Universitas Brawijaya, Indonesia.

*Corresponding author: Nandy Agustin Syakarofath, Fakultas Psikologi, Universitas Muhammadiyah

Malang, Malang, Indonesia. E-mail: nandysyakarofath@umm.ac.id

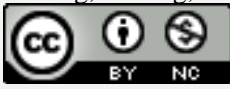

This work is licensed under a Creative Commons Attribution-NonCommercial 4.0 International License.

How to cite this article in accordance with the American Psychological Association (APA) $7^{\text {th }}$ guidelines:

Syakarofath, N. A. (2021). Masalah emosi dan perilaku remaja: Studi awal masalah kesehatan mental di $\begin{array}{lllll}\text { Kabupaten } & \text { Pamekasan, } & \text { Indonesia. } & \text { MEDIAPSI, } & 7(2),\end{array}$ https://doi.org/10.21776/ub.mps.2021.007.02.6 


\section{Pendahuluan}

Masa remaja bukanlah masa transisi yang sederhana dari masa kanak-kanak ke dewasa, tetapi masa perubahan kedewasaan yang besar di mana pondasi penting dari perilaku dan emosi orang dewasa terbentuk (Öner dkk., 2021; Eryılmaz 2012). Perubahan cepat dalam kondisi sosial, budaya, dan ekonomi pada saat ini menyebabkan individu mengalami masa remaja lebih sulit karena umumnya diterima sebagai masa yang penuh gejolak dalam perkembangan manusia (Özmen dkk., 2011; Eskin dkk., 2008). Umumnya, para remaja mengalami berbagai persoalan terkait citra tubuh, identitas diri, identitas seksual, harga diri, kemandirian dari orangtua, individualisasi, hubungan dengan teman sekolah dan teman sebaya, serta rencana masa depan (Eryılmaz, 2012).

Menurut sensus populasi yang telah dilakukan di Indonesia pada tahun 2012, populasi remaja merupakan populasi terbanyak dibandingkan dengan populasi lainnya. Hasil survei menyebutkan data bahwa terdapat $10-25 \%$ remaja yang mengalami gangguan mental serius yang disebabkan oleh tidak tertanganinya masalah di masa sebelumnya, yaitu kanakkanak (Bayat dkk., 2021; Öztop, 2012). Kieling dkk. (2011) bahkan menyebutkan bahwa terdapat satu dari lima remaja yang ada di seluruh dunia mengalami masalah kesehatan mental. Kondisi yang lebih serius dipaparkan World Health Organisation atau WHO dimana salah satu penyebab terbesar kematian remaja dengan disabilitas (DALYs lost) adalah self harm, yaitu tindakan yang dilakukan oleh remaja untuk melukai dirinya sendiri (WHO, 2017, 2018).
Anak-anak dan remaja adalah bagian populasi yang dapat menentukan wajah dunia di masa mendatang, sehingga penting untuk diperhatikan terkait segala aspek kehidupannya, termasuk di bidang kesehatan. Banyak jumlah remaja yang terdata mengalami gangguan mental. Meskipun demikian, belum ada akses layanan dan cara penangan yang tepat untuk remaja tersebut. Apabila tidak tertangani, masalah yang dialami remaja tersebut dapat menyebabkan dampak negatif berkepanjangan bagi mereka. Hal ini tidak hanya berdampak terhadap remaja itu sendiri tetapi juga terhadap orang lain. Oleh karenanya, penelitian terkait status kesehatan mental perlu dilakukan di berbagai daerah agar dapat terdeteksi dan diketahui jumlah riil yang terjadi di lapangan. Tujuannya adalah untuk memahami seberapa luas permasalahan remaja yang terjadi. Pemahaman ini bermanfaat untuk melakukan pemetaan sebagai upaya penanganan permasalahan remaja. Secara lebih spesifik, penelitian ini bertujuan mengidentifikasi permasalahanpermasalahan remaja dari segi gender mereka.

\section{Metode}

\section{Partisipan dan desain penelitian}

Sejumlah 237 remaja di Kabupaten Pamekasan berpartisipasi aktif dalam penelitian ini, dimana jumlah tersebut diperoleh menggunakan teknik random sampling dengan bantuan situs random.org. Menggunakan prosedur ini, subjek penelitian yang direkrut secara keseluruhan berjumlah 237 remaja berusia 15-18 tahun. Subjek remaja perempuan berjumlah 102 orang (43\%), sedangkan subjek remaja laki-laki berjumlah 135 orang $(57 \%)$. Adapun sebaran usia subjek 
yang berada pada rentang 15 tahunberjumlah 13 orang (5.5\%), 16 tahun berjumlah 112 orang (47.3\%), 17 tahun berjumlah 96 orang (40.5\%), dan 18 tahun berjumlah 16 orang $(6.8 \%)$. Desain penelitian adalah kuantitatif deskriptif, untuk mengeksplorasi sejauh mana partisipan memiliki permasalahan emosi dan perilaku yang berbeda atau sama dilihat dari segi jenis kelamin atau gender mereka.

\section{Prosedur dan pengukuran}

Randomisasi dilakukan dengan mendata terlebih dahulu jumlah Sekolah Menangah Atas yang ada di Kabupaten Pamekasan. Tahap berikutnya adalah melakukan pengacakan untuk menentukan sampel penelitian via website random.org. Hasil randomisasi atau pengacakan adalah terpilihnya dua sekolah, yaitu sekolah A (SMA Swasta), dan sekolah B (SMA Negeri). Kedua sekolah tersebut kemudian menjadi lokasi pengambilan data.

Instrumen penelitian yang digunakan adalah the Strengths and Difficulties Questionnaire (SDQ) versi bahasa Indonesia yang dikembangkan oleh Goodman (Goodman, 1997; Goodman dkk., 1998). Instrumen ini telah memiliki versi terjemahan bahasa Indonesia yang dilakukan oleh Wiguna dkk. (2010). Ada lima aspek utama yang diungkap dalam skala tersebut, yaitu emotional problem, conduct problem, hyperactivity, peer problem, dan prosociality (Goodman dkk., 2010). SDQ yang sudah diterjemahkan ke dalam bahasa Indonesia memiliki nilai reliabilitas sebesar $\alpha=.77$, skor ROC cutoff $\geq 5$ sebagai instrumen skrinning. Sementara itu, nilai sensitivitas sebesar 0.67 dan nilai spesivisitas sebesar 0.68 , serta nilai $\mathrm{LR}(+)=2.09$ dan $\mathrm{LR}(-)=0.49$ (Oktaviana \& Wimbarti, 2014).

Cara pengisian instrumen dilakukan dengan memilih satu dari tiga jawaban yang tersedia dan dianggap paling sesuai dengan kondisi diri remaja, yaitu tidak benar (0), agak benar (1), dan benar (2). Adapun keseluruhan total butir pertanyaan berjumlah 20, dimana masing-masing aspek didalamnya memiliki 5 butir pertanyaan. Selain mengungkap 5 aspek, yaitu emotional problem, conduct problem, hyperactivity, peer problem, dan prosociality, SDQ juga mengungkap status kesehatan mental secara umum melalui skor totalnya dengan tiga kategori yaitu: 1) normal, 2) borderline, dan 3) abnormal.

Etika penelitian yang dilaksanakan di dalam penelitian ini dilandaskan pada persetujuan dan kesediaan subjek penelitian untuk berpartisipasi dalam penelitian ini yang dibuktikan dengan pengisian informed consent. Penelitian ini dilakukan secara sukarela, tanpa ada paksaan dalam bentuk apapun. Dengan demikian, subjek penelitian dapat menolak jika kemudian tidak bersedia melanjutkan serangkaian pertanyaan dalam penelitian ini.

\section{Hasil}

Analisis data dilakukan menggunakan Jeffreys's Amazing Statistics Program atau JASP version 0.15 for windows (JASP Team, 2021) yang menghasilkan data deskriptif statistik untuk memperoleh gambaran prevalensi masalah emosi dan perilaku remaja. Selanjutnya sebaran data deskriptif secara terperinci dapat dilihat pada Tabel 1. Tabel 1 menunjukkan bahwa mayoritas partisipan berjenis kelamin laki-laki (57\%) 
dan sisanya berjenis kelamin perempuan (43\%). Secara umum, berdasarkan skor total SDQ, subjek laki-laki yang memiliki masalah kesehatan mental dalam kategori abnormal berjumlah $83 \%$ ), borderline berjumlah $14.8 \%$ ), dan normal berjumlah $2.2 \%$. Jumlah subjek perempuan yang memiliki masalah kesehatan mental dalam kategori abnormal berjumlah $86.2 \%$, borderline berjumlah $11.8 \%$, dan normal berjumlah $2 \%$. Adapun nilai mean atau rata-rata terkait status kesehatan mental pada laki-laki adalah sebesar 2.81 dan pada perempuan sebesar 2.84. Hasil skrinning berdasarkan jenis kelamin secara umum menunjukkan adanya indikasi masalah status kesehatan mental.

Analisis lebih lanjut terkait jenis difficulties terkait emotional problem baik pada subjek laki-laki dan perempuan mayoritas berada pada rentang normal (laki-laki $80 \%$, perempuan $87.2 \%$ ). Pada masalah conduct problem, baik laki-laki maupun perempuan mayoritas berada pada rentang abnormal (laki-laki 76.2\%, perempuan $86.2 \%$ ). Terkait hiperactivity, mayoritas laki-laki dan perempuan berada pada rentang normal (laki-laki 93.3\%, perempuan 91\%). Terkait peer problem, baik laki-laki dan perempuan mayoritas berada pada taraf borderline (laki-laki $44.5 \%$, perempuan $44 \%$ ). Selanjutnya, terkait prosociality atau prososial behavior, mayoritas laki-laki dan perempuan berada pada taraf normal (lakilaki $77.8 \%$, perempuan $83 \%$ ). Data tersebut konsisten dengan hasil perhitungan mean pada masing-masing jenis kelamin. Perhitungan mean ini menunjukkan bahwa permasalahan utama terletak pada conduct problem (nilai mean laki-laki $=2.68$, nilai mean perempuan $=$ 2.81). Selanjutnya, terkait peer problem, nilai mean laki-laki $=2.27$, nilai mean perempuan $=2.15$.

Tabel 1. Status Kesehatan Mental Remaja Berdasarkan Jenis Kelamin.

\begin{tabular}{lcccc}
\hline \multicolumn{1}{c}{ Demografi } & $\begin{array}{c}\text { Laki-laki } \\
N=135(57 \%)\end{array}$ & $M$ & $\begin{array}{c}\text { Perempuan } \\
N=02(43 \%)\end{array}$ & $M$ \\
\hline $\begin{array}{lccc}\text { Status kesehatan mental } \\
\text { Normal }\end{array}$ & $3(2.2 \%)$ & 2.81 & $2(2 \%)$ & 2.84 \\
Borderline & $20(14.8 \%)$ & & $12(11.8 \%)$ & \\
Abnormal & $112(83 \%)$ & & $88(86.2 \%)$ & \\
\hline Emotional problem & & & & \\
Normal & $108(80 \%)$ & 1.30 & $9(87.2 \%)$ & 1.17 \\
Borderline & $14(10.4 \%)$ & & $4(3.9 \%)$ & \\
Abnormal & $13(9.6 \%)$ & & & \\
\hline Conduct problem & & & $11(10.8 \%)$ & 2.83 \\
Normal & $11(8.2 \%)$ & 2.68 & $88(86.2 \%)$ & \\
Borderline & $21(15.6 \%)$ & & & \\
Abnormal & $103(76.2 \%)$ & & $5(91 \%)$ & 1.13 \\
\hline Hyperactivity & & & $4(4 \%)$ & \\
Normal & $126(93.3 \%)$ & 1.10 & & \\
Borderline & $5(3.7 \%)$ & & & \\
Abnormal & $4(3 \%)$ & & & \\
\hline
\end{tabular}


Tabel 1. (Lanjutan).

\begin{tabular}{lcccc}
\hline \multicolumn{1}{c}{ Demografi } & $\begin{array}{c}\text { Laki-laki } \\
N=135(57 \%)\end{array}$ & $M$ & $\begin{array}{c}\text { Perempuan } \\
N=02(43 \%)\end{array}$ & $M$ \\
\hline Peer problem & $19(14 \%)$ & 2.27 & $21(21 \%)$ & \\
Normal & $60(44.5 \%)$ & & $36(44 \%)$ & 2.15 \\
Borderline & $56(41.5 \%)$ & & $85(83 \%)$ & \\
Abnormal & $105(77.8 \%)$ & & $13(13 \%)$ & 1.21 \\
\hline Prosocial behavior & $18(13.3 \%)$ & & $4(4 \%)$ & \\
Normal & $12(8.9 \%)$ & & & \\
Borderline & & & \\
Abnormal & &
\end{tabular}

Keterangan. $N=$ jumlah responden laki-laki atau perempuan. $M=$ nilai rata-rata.

\section{Diskusi}

Pemetaan terkait kondisi kesehatan mental remaja di Kabupaten Pamekasan didapatkan data bahwa secara keseluruhan baik remaja laki-laki maupun remaja perempuan mengalami masalah kesehatan mental. Namun demikian, masalah yang paling serius dihadapi adalah conduct problem dan peer problem. Artinya, baik remaja laki-laki maupun remaja perempuan sama-sama mengalami peluang atau kerentanan untuk mengalami masalah kesehatan mental. Hal ini sesuai dengan pendapat Schijven dkk. (2021) bahwa secara umum baik laki-laki dan perempuan sama-sama memiliki faktor risiko maupun faktor protektif yang dapat mempengaruhi masalah kesehatan mental yang mereka hadapi. Meskipun demikian, tingkat keparahan permasalahan yang dihadapi remaja laki-laki dan remaja perempuan dapat berbeda sesuai pengalaman hidup masing-masing. Mengacu pada pendapat Schijven dkk. (2021), wanita cenderung mengalami internalizing problem, sementara laki-laki cenderung mengalami externalizing problem.

Pada aspek emotional problem, data kedua jenis kelamin sama-sama berada pada rentang normal. Temuan ini tidak MEDIAPSI | 2021, Vol. 7, No. 2, 141-149 selaras dengan hasil riset Ediati (2015), yang melaporkan bahwa remaja perempuan cenderung mengalami masalah emosi (khususnya yaitu kecemasan/depresif, penarikan diri dari lingkungan dan pergaulan, keluhan somatik, kesulitan berinteraksi dan menjalin relasi dengan orang lain, masalah konsentrasi, dan internalizing problem) lebih tinggi dibandingkan dengan remaja laki-laki. Penyebab tingginya perempuan dibandingkan laki-laki dalam masalah emosi disebabkan oleh beberapa faktor yang dimiliki perempuan. Faktor-faktor tersebut mencakup masalah hormonal, aktivitas otak dalam merespon stres (respon sumbu hipotalamus-hipofisisadrenal ynag cenderung lebih tidak peka), rendahnya self esteem, ketidak percayaan diri terhadap tubuh yang dimiliki, tingkat stressor interpersonal yang lebih tinggi, kekerasan yang pernah dialami, trauma dan pelecehan seksual yang pernah dialami, hingga isu terkait kesetaraan dan diskriminasi gender (Kuehner, 2017). Namun demikian, penjelasan terkait kondisi emosi antara remaja perempuan dan remaja laki-laki pada penelitian ini berada pada taraf normal karena kedua gender sama-sama mampu 
mengembangkan kecerdasan emosional yang baik. Sebagai konsekuensinya, masalah emosi yang dialami dapat dikelola dengan efektif dan tidak semakin berkembang (Meshkat \& Nejati, 2017). Individu-individu yang memiliki kapasitas kecerdasan emosi yang baik mampu memproses informasi emosi secara akurat dan efisien, yang selanjutnya mendorong pertumbuhan intelektual mereka (Goleman, 2012).

Aspek conduct problem dan peer problem kebanyakan remaja laki-laki maupun perempuan pada penelitian ini berada pada rentang borderline dan abnormal. Artinya, mayoritas remaja yang menjadi subjek penelitian ini mengalami masalah perilaku dan masalah dengan teman sebayanya terlepas dari latar belakang gender yang dimiliki. Terjadinya permasalahan dengan teman sebayanya disebabkan oleh berbagai faktor, seperti keinginan untuk diterima oleh kelompok sebaya. Remaja cenderung melakukan segala tindakan yang maladaptif dan merusak hingga merugikan diri sendiri dan orang lain (Cakirpaloglu dkk., 2016). Tindakan maladaptif dan merusak tersebut merupakan tindakan yang mencerminkan adanya masalah perilaku atau conduct problem.

Berbeda dengan hasil penelitian sebelumnya, hasil uji deskriptif mengenai hiperaktivity pada penelitian ini menunjukkan rentang normal. Artinya, subjek laki-laki dan perempuan pada penelitian ini tidak mengalami masalah hyperactivity. Sementara itu, Rosenfield dan Smith (2010) menemukan bahwa lakilaki daripada perempuan lebih cenderung menunjukkan masalah perilaku yang didalamnya terdapat masalah hiperaktifitas. Meski demikian, hasil MEDIAPSI | 2021, Vol. 7, No. 2, 141-149 penelitian ini didukung oleh penelitian sebelumnya (Skogli dkk., 2013) yang menunjukkan bahwa baik laki-laki maupun perempuan memiliki kemungkinan untuk mengalami masalah hiperaktivity.

Selanjutnya pada aspek prososial, baik remaja laki-laki maupun perempuan dalam penelitian ini sama-sama memiliki perilaku prososial yang tinggi. Jika dikaitkan dengan perkembangan remaja, hal tersebut disebabkan oleh keinginan remaja untuk bisa diterima oleh lingkungannya, yang salah satu di antaranya adalah termasuk teman sebaya. Motif ini mendorong remaja menunjukkan perilaku yang normatif (Juntilla dkk., 2006). Tingginya masalah teman sebaya yang dihadapi oleh subjek penelitian selaras dengan tingginya kecenderungan perilaku prososial yang mereka ditunjukkan. Contoh dari perilaku prososial tersebut adalah sikap suka memberi pertolongan dan berbagi dengan sesama, bertindak secara sukarela dan tanpa pamrih serta memperhatikan kondisi diri maupun orang disekitarnya. Dalam hubungan sosial, munculnya perilaku ini menandakan motif individu untuk membangun maupun memelihara hubungan sosial (Agnew \& Le, 2015).

\section{Kesimpulan}

Berdasarkan temuan penelitian, dapat disimpulkan bahwa masalah kesehatan mental yang dihadapi remaja laki-laki dan remaja perempuan tergolong cukup serius, terutama pada aspek conduct problem dan peer problems. Implikaisnya, kedua aspek tersebut perlu mendapatkan perhatian serius dari berbagai pihak terutama pemerhati pendidikan, orangtua, dan pihak sekolah. Langkah ini sangat penting dilakukan agar potensi 
permasalahan emosional dan perilaku remaja laki-laki maupun remaja perempuan tidak semakin berkembang menjadi permasalahan yang lebih serius.

\section{Daftar Pustaka}

Agnew, C. R., \& Le, B. (2015). Prosocial behavior in close relationships: An interdependence approach. In D. A. Schroeder \& W. G. Graziano (Eds.), The Oxford handbook of prosocial behavior (pp. 362-375). Oxford University Press. https://doi.org/10.1093/oxfor $\mathrm{dhb} / 9780195399813.013 .021$

Bayat, N., Fokkema, T., Mujakovic, S., \& Ruiter, R. A. (2021). Contextual Correlates of Loneliness in Adolescents. Children and Youth Services Review, 127, 1-6. https://doi.org/10.1016/j.childyouth. 2021.106083

Cakirpaloglu, S. D., Lemrova, S., Kvintova, J., \& Vevodova, S. (2016). Conformity, peer presure, popularity and risk behavior among adolescents. In 9th Annual International Conference of Education Research and Innovation Proceeding (pp. 4078-4086). https://doi.org/10.21125/iceri.2016. 0196

Ediati, A. (2015). Profil problem emosi/perilaku pada remaja pelajar SMP-SMA di Kota Semarang. Jurnal Psikologi Undip, 14(2), 190-198. https://doi.org/10.14710/jpu.14.2.19 0-198

Eryilmaz, A. (2012). A model for subjective well-being in adolescence: Need satisfaction and reasons for living. Social

Indicators

Research, 107(3),

561-574. https://doi.org/10.1007/s11205-0119863-0

Eskin, M., Ertekin, K., \& Demir, H. (2008). Efficacy of a problemsolving therapy for depression and suicide potential in adolescents and young adults. Cognitive Therapy and Research, 32(2), 227-245. https://doi.org/10.1007/s10608-0079172-8

Goleman, D. (2012). Emotional intelligence: Why it can matter more than IQ. Bantam.

Goodman, A., Lamping, D. L., \& Ploubidis, G. B. (2010). When to use broader internalising and externalising subscales instead of the hypothesised five subscales on the Strengths and Difficulties Questionnaire (SDQ): data from British parents, teachers and children. Journal of Abnormal Child Psychology, 38(8), $\quad$ 1179-1191. https://doi.org/10.1007/s10802-0109434-X

Goodman, R. (1997). The Strengths and Difficulties Questionnaire: a research note. Journal of Child Psychology and Psychiatry, 38(5), 581-586.

https://doi.org/10.1111/j.1469-

7610.1997.tb01545.x

Goodman, R., Meltzer, H., \& Bailey, V. (1998). The strengths and difficulties questionnaire: A pilot study on the validity of the selfreport version. European Child \& Adolescent Psychiatry, 7(3), 125130. 
https://doi.org/10.1007/s007870050

057

JASP Team (2021). JASP (Version 0.15)

[Computer software].

Junttila, N., Voeten, M., Kaukiainen, A., \& Vauras, M. (2006). Multisource Assessment of Children's Social Competence. Educational and Psychological Measurement, 66(5), 874-895.

https://doi.org/10.1177/0013164405 285546

Kieling, C., Baker-Henningham, H., Belfer, M., Conti, G., Ertem, I., Omigbodun, O., ... Rahman, A. (2011). Child and adolescent mental health worldwide: Evidence for action. The Lancet, 378(9801), 1515-1525.

https://doi.org/10.1016/S01406736(11)60827-1

Kuehner, C. (2017). Why is depression more common among women than among men?.The Lancet Psychiatry, 4(2), 146-158. https://doi.org/10.1016/S22150366(16)30263-2

Meshkat, M., \& Nejati, R. (2017). Does emotional intelligence depend on gender? A study on undergraduate english majors of three Iranian Universities. SAGE Open. https://doi.org/10.1177/2158244017 725796

Oktaviana, M., \& Wimbarti, S. (2014). Validasi Klinik Strenghts and difficulties questionnaire (SDQ) sebagai instrumen skrining gangguan tingkah laku. Jurnal Psikologi. $\quad 41(1), \quad$ 101-114. https://doi.org/10.22146/jpsi.6961

Öner, H., \& Karabudak, S. S. (2021). Negative emotions and coping MEDIAPSI | 2021, Vol. 7, No. 2, 141-149 experiences of nursing students during clinical practices: A focus group interview. Journal of Psychiatric Nursing, 12(3), 205-215. https://doi.org/10.14744/phd.2021.59 480

Özmen, O., \& Sümer, Z. H. (2011). Predictors of risk-taking behaviors among Turkish adolescents. Personality and Individual Differences, 50(1), 4-9. https://doi.org/10.1016/j.paid.2010.0 7.015

Öztop, D. B., Taşdelen, B. İ., PoyrazoğLu, H. G., Ozsoy, S., Yilmaz, R., Şahın, N., ... \& Bozkurt, S. (2016). Assessment of psychopathology and quality of life in children and adolescents with migraine. Journal of Child Neurology, 31(7), 837-842. https://doi.org/10.1016/j.cogdev.202 0.100923

Rosenfield, S., \& Smith, D. (2010). Gender and mental health: Do men and women have different amounts or types of problems? In T. L. Scheid \& T. N. Brown (Eds.), A handbook for the study of mental health: Social contexts, theories, and systems (pp. 256-267). Cambridge University Press.

Schijven, E. P., VanDerNagel, J. E., Otten, R., Lammers, J., \& Poelen, E. A. (2021). Take it personal! Development and modelling study of an indicated prevention programme for substance use in adolescents and young adults with mild intellectual disabilities and borderline intellectual functioning. Journal of Applied Research in Intellectual Disabilities, 34(1), 307-315. https://doi.org/10.1111/jar.12808 
Skogli, E. W., Teicher, M. H., Andersen, P. N., Hovik, K. T., \& Øie, M. (2013). ADHD in girls and boysgender differences in co-existing symptoms and executive function measures. BMC Psychiatry, 13(1), 112. https://doi.org/10.1186/1471244X-13-298

Wiguna, T.. (2010). Masalah emosi dan perilaku pada anak dan remaja di Poliklinik Jiwa Anak dan Remaja RSUPN dr. Ciptomangunkusumo (RSCM), Jakarta. Sari Pedatri, 12 (4), 270-277. https://doi.org/10.14238/sp12.4.201 0.270-7

World Health Organization. (2017). Global Accelerated Action for the Health of Adolescents (AAHA!). Guidance to Support Country Implementation.

http://apps.who.int/iris/bitstream/ha ndle/10665/255415/9789241512343 $-$

eng.pdf;jsessionid $=1 \mathrm{BC} 7566 \mathrm{D} 91 \mathrm{C} 8$ 6EA0B3\%20BBE835B92DD

World Health Organization. (2018). Adolescent Health The Missing Population in Universal Health Coverage.

https://www.who.int/pmnch/media/e vents/Adolescent-Health-MissingPopulation-in-UHC.pdf?ua=1 